\title{
How rural residence and gender associate with Mental Health: a cross-sectional study among Chinese early adolescents
}

Xinshu She ( $\nabla$ xinshe@stanford.edu )

Stanford University https://orcid.org/0000-0003-4717-4924

Deqing Zhao

Zhijin County Medical Office

Mengying Li

Johns Hopkins University Bloomberg School of Public Health

\section{Research}

Keywords: mental health disorders, youth disability, urban-rural inequalities

Posted Date: August 11th, 2020

DOI: https://doi.org/10.21203/rs.3.rs-51089/v1

License: (c) (i) This work is licensed under a Creative Commons Attribution 4.0 International License.

Read Full License 


\section{Abstract}

Background: Mental health disorders are the leading cause of disability in youth globally. China has the world's second largest pediatric population with growing urban-rural inequalities.

Objectives: 1) to examine the prevalence and gender differences in drug use, depressive symptoms, social support and externalizing behaviors in adolescents from an underserved rural community; 2 ) to compare results to a known urban sample

Methods: A cross-sectional study was conducted among children 12-14 years-old from rural Guizhou ( $N=76$ ) using the 2003 Global School-based Student Health Survey. Prevalence and gender differences of 19 mental health outcomes were calculated and compared to those from a public urban Beijing sample $(N=1,629)$. Associations of outcomes with gender and rural residence were assessed using multivariate logistic regression models in a combined analysis.

Results: The prevalence of 9 out of the 19 investigated outcomes was significantly higher in the rural sample. In rural Guizhou, female gender was associated only with lower prevalence of physical fights. In the combined analysis, rural residence was associated with higher risks of lifetime troubles due to drinking, loneliness, insomnia, hopelessness, injuries and absenteeism. Girls had lower risks of recent drinking, inebriation, troubles due to drinking, recent smoking, fights, injures and bullying victimization compared to boys.

Conclusion: Higher risks of excessive drinking, depressive symptoms, poor social support, and externalizing behaviors were found in rural adolescents compared to their urban peers. Girls had lower risks of drug use, poor peer support and externalizing behaviors. These findings call for targeted interventions informed by contextual and gender specifications.

\section{Background}

Mental health and substance use disorders are the leading cause of disability in the world (GBD, 2017) and in children and adolescents (Erskine et al., 2014). Ninety percent of the affected youth live in low- and middle-income countries-LMICs (Fleischmann \& De Leo, 2014) but only $10 \%$ of publications come from these countries (Saxena et al., 2006). The disease burden in LMICs is often overwhelming due to insufficient economic and healthcare resources (Vikram et al., 2013) and evidence from developed countries may not apply contextually (Maselko, 2017). Mental Health research in children and adolescents in LMIC is urgently needed to combat the burden of disease and to develop effective interventions to help billions of vulnerable youth develop their full potential (Kieling et al., 2011).

China is a high-middle-income country with the world's second largest youth population (UNFPA report, 2014) and growing urban-rural economic inequality (Zhou \& Song, 2016). Though the country's overall development has improved some pediatric physical health disparities such as malnutrition (Dong et al., 2019), little is known about mental health disparities. A few recent publications showed concerning 
patterns of higher prevalence of substance use (She et al., 2016), anxiety (Liu et al., 2018), lower selfesteem and social support (Zhang et al., 2017) in rural youth. The causes are likely multifactorial. Rural children reportedly have lower rates of preschool and kindergarten enrollment, poorer social skills and less caregiver involvement in their education (Chen et al., 2015). In addition, more than 20 million have been impacted by the family disruption due to parental out-migration in the last few decades (Gao et al., 2010), which increased risks in educational and health problems (Meng \& Yamauchi, 2017). Rural China is also known for traditional gender roles-girls are often assigned more domestic responsibilities and receive fewer resources (Tian et al., 2018). Historically this led to higher female child mortality (Ren, 1995) and poorer health (Li et al., 2004). Recently the gender gap seems to be closing for all health outcomes except for mental health (Zhou et al., 2016). This phenomenon is poorly understood.

Guizhou (Appendix 1) is the poorest province in China based on per capita income (National Bureau of Statistics of China, 2014). Zhijin county is a mountainous area of Guizhou particularly isolated due to difficult transportation (at least 6 hours of cliff-side bus ride from the nearest station at the time of data collection). In addition to limited economic and healthcare resources, more than one third of the rural children have been "left behind" by parents due to out-migration (All China Women's Federation, 2013). These children suffer from long-term separation from parents during formative years and often live with overburdened relatives or grandparents (Zhao et al., 2018). This phenomenon of "left-behind-children" is common among LMICs and has been associated with higher rates of depression, anxiety, suicidal ideation, conduct disorder and substance use (Fellmeth et al., 2018).

\section{Objectives}

1) to examine the prevalence and gender differences in drug use, depressive symptoms, social support and externalizing behaviors in early adolescents in an underserved rural county in China; 2) to compare outcomes to those in a public urban sample; 3 ) to examine the associations of gender and residence with mental health outcomes in all subjects

\section{Methods}

This study used cross-sectional survey data collected by the authors in grades 4-6 (ages 11-14) at two underserved schools in rural Zhijin County (Guizhou province, China). A total of 100 students completed the Chinese version of the 2003 Global School Health Survey, or GSHS (WHO, 2003). The sample size satisfied our power calculation using an a of 0.05 and a hypothesized between-group difference of $10 \%$. The data collection was twofold. First, two local schools participating in a community library project were contacted and both agreed to enroll in the study. After obtaining consent from the principals, we randomly selected 2 classrooms from each school (cluster randomization) with fifty students each. All guardians of the 100 students gave verbal assesnt prior to student participation. The urban Beijing sample included in the rural-urban analysis was previously published by the Chinese Center for Disease Control (CCDC) in collaboration with the World Health Organization and the US CDC (USCDC, 2016). The same 2003 GSHS was used in a 2-stage cluster sample selection process. First, a list of all middle 
schools in Beijing was gathered and schools were selected with probability proportional to enrollment size. Next, classes were randomly selected as clusters and all students in these classes were eligible to participate. The school response rate in Beijing was $100 \%$ and the student response rate was $99 \%$. A total of 2,348 students ages 12-16 were included in the Beijing sample. For this study students ages 12-14 were chosen to represent early adolescents. Our analysis included 76 Zhijin students and 1,629 Beijing students.

For the survey, the 2003 GSHS is a widely used tool validated and applied by the WHO in many countries in conjunction with local governments (WHO, 2003). It covered 68 core questions in 8 categories:

"Hygiene," "Drug Use," "Mental Health," "Nutrition," "Activity," "Protective Factors," "Tobacco," and "Safety." Table 1 lists the 19 survey questions from the Chinese GSHS used to create all the binary categorical outcome variables in our study. We grouped them into four domains for conceptualization: "drug use", "depression", "social support" and "externalizing behaviors". 
Table 1

Mental health questions of the Chinese 2003 Global School-based Student Health Survey used in this analysis (English translation)

\section{Variable Question}

1. Recent In the past 30 days, how many alcoholic drinks did you have?

drinking

2. Ever drunk In your lifetime, how many times have you ever gotten drunk?

3. Trouble In your lifetime, how many times have you ever had hangover, felt sick, or gotten with alcohol into trouble because of alcohol?

4. Recent In the past 30 days, on how many days have you smoked a cigarette or more? smoking

5. Passive In the past 7 days, on how many days did other people smoke around you? smoking

6. Other drugs In your lifetimes, how many times have you ever used any drugs such as marijuana, methamphetamine, Ecstasy, heroine?

7. Loneliness In the past 12 months, how many times have you felt lonely?

8. Insomnia In the past 12 months, how often have you lost sleep due to worries?

9. In the past 12 months, did you ever feel so sad or hopeless almost every day for 2 Hopelessness weeks or more in a row that you stopped doing your usual activities?

10. Suicidal In the last 12 months, how many times have you seriously considered suicide? ideation

11. Suicidal In the last 12 months, how many times have you seriously planned a suicide? plan

12. Close How many close friends do you have?

friends

13. Helpful In the past 30 days, how often did you find most schoolmates kind or helpful? schoolmates

14. Parental In the past 30 days, how often did your guardians really knew what you were doing supervision with your free time?

15. Parental In the past 30 days, how often did your guardians understand your problems or understanding worries?

16. Fighting In the past 12 months, how many times were you involved in a physical fight?

17. Injuries In the past 12 months, how many times were you seriously injured?

18. Bullying In the past 30 days, on how many days were you bullied?

19. Absence In the past 30 days, on how many days were you absent without permission? 
For the analysis, we used descriptvie statistics to calculate the prevalence of each outcome variable in the rural sample. Then we compared the results with those from the urban sample using the $\chi^{2}$ test. Next, we calculated the prevalence of each outcome variable in the rural sample by gender. The $\chi^{2}$ test was again used to assess gender differences by statistical significance. The same process was applied to examine gender differences in the urban sample. Finally, multivariate logistic regression models were applied to a combined rural-urban sample $(\mathrm{N}=1,705)$ accounting for the effects of clustered sampling to examine the associations between each mental health outcome, gender and residence adjusting for age, grade, height and weight. In sensitivity analysis, interaction terms between gender and residency were added to test potential effect modification on the outcomes. All analyses were performed using $95 \%$ confidence intervals. A two-sided $P$ value of $<0.05$ was used to define statistical significance. Data analysis was completed using STATA version 15.0 (StataCorp, College Station, TX).

\section{Results}

Table 2 summaries the background characteristics of rural and urban students.

Table 2

Background characteristics in rural $(N=76)$ and urban $(N=1,629)$ samples, ${ }^{*} \mathrm{p}<0.05$

\begin{tabular}{|c|c|c|c|}
\hline & Zhijin (rural) & Beijing (urban) & $P$-value \\
\hline \multicolumn{4}{|l|}{ Gender, freq (\%) } \\
\hline Female & 54.4 & 54.2 & $0.97 *$ \\
\hline Male & 45.6 & 45.8 & \\
\hline Mean age (SD) & $12.6(0.7)$ & $13.3(0.7)$ & $<0.01^{*}$ \\
\hline \multicolumn{4}{|l|}{ Grade, freq (\%) } \\
\hline 6 & 14.5 & 38.5 & $<0.01^{*}$ \\
\hline 7 & 65.8 & 41.9 & \\
\hline 8 & 19.7 & 19.4 & \\
\hline 9 & 0.0 & 0.3 & \\
\hline Height (m), mean (SD) & $1.35(0.13)$ & $1.60(0.08)$ & $<0.01^{\star}$ \\
\hline Weight (kg), mean (SD) & $32.3(7.23)$ & $50.6(11.60)$ & $<0.01^{*}$ \\
\hline
\end{tabular}

Gender distribution was close to even (54.4\% female in the rural sample and $54.1 \%$ in the urban sample). Both samples included students ages 12-14 with a younger distribution in the rural sample (mean of 12.4 , SD 0.7) compared to the urban sample (mean of 13.3, SD 0.7). Both rural and urban samples included participants from grade $6-8$, with the highest proportion of students in garde $7(65.8 \%$ of the rural sample and $41.9 \%$ of the urban sample). The rural sample had a lower mean height of $1.35 \mathrm{~m}$ (SD 
$0.13)$ vs. $1.60 \mathrm{~m}$ (SD 0.08) in the urban sample and a lower mean weight of $32.3 \mathrm{~kg}$ (SD 7.23) vs. $50.6 \mathrm{~kg}$ (SD 11.60) consistent with the rural sample's younger mean age.

Table 1 present the prevalence of all investigated mental health outcomes first in the rural sample and then compared to the urban sample. Under the "drugs" category, the rural sample showed higher prevalence of ever getting into trouble due to alcohol $(14.9 \%$ vs. $3.7 \%$ in the urban sample, $p<0.001)$ and ever using drugs other than alcohol and cigarettes ( $5.3 \%$ vs. $0.6 \%$ in the urban sample, $p<0.001)$. Under "depression", rural students showed no significantly different prevalence of suicidal ideation in the past year $(8.2 \%$ vs. $14.2 \%$ in urban students, $p=0.15)$ but higher prevalence of ever feeling hopeless for 2 weeks straight in the past year $(32.0 \%$ vs. $18.2 \%$ in the urban sample, $p=0.003)$. Under "social support", rural students reported higher prevalence of rarely or never finding schoolmates helpful (38.2\% vs. $17.9 \%$ in urban students, $p<0.001)$, rarely or never having guardians supervise their free time $(46.1 \% \mathrm{vs} .30 .1 \%$ in urban students, $p=0.003)$ and rarely or never having guardians understand their problems $(63.2 \%$ vs. $34.0 \%$ in urban students, $p<0.001$ ) all in the past month. Under "externalizaing behaviors", rural students reported higher prevalence of being seriously injuried in the past year $(46.7 \%$ vs. $16.2 \%$ in urban students, $p<0.001$ ), being bullied ( $47.4 \%$ vs. $20.3 \%$ in urban students, $p<0.001)$ and missing school without permmission $(14.7 \%$ vs. $4.8 \%$ in urban students, $p<0.001)$ both in the past month.

Figure 1 (also see supplementary table 1 for detailed data) compares the prevalence of all mental health outcome measures by gender first in the rural sample, and then in the urban sample. In rural Zhijin, only the prevalence of getting into physical fights in the past year was statistically different by gender $(41.9 \%$ of boys vs. $2.7 \%$ of girls, $p<0.001)$. In the urban sample, boys reported significantly higher prevalence of many outcomes compared to girls-drinking in the past month ( $12.1 \%$ vs. $7.7 \%$ in girls, $p=0.002)$, ever getting drunk ( $9.7 \%$ vs. $5.3 \%$ in girls, $p=0.002)$, ever getting into trouble because of alcohol $(5.1 \%$ vs. $2.5 \%$ in girls, $p=0.006)$, smoking in the past month $(10.7 \%$ vs. $1.6 \%$ in girls, $p<0.001)$, experiencing passive smoking in the past week ( $61.5 \%$ vs. $54.8 \%$ in girls, $p=0.005)$, rarely or never finding their schoolmates helpful in the past month $(23.3 \%$ vs. $13.3, p<0.001)$, getting into physical fights in the past year $(25.1 \%$ vs. $5.9 \%$ in girls, $p<0.001)$, getting injuried in the past year $(15.8 \%$ vs. $11.3 \%$ in girls, $p=0.001)$ and being bullied in the past month $(22.3 \%$ vs. $16.8 \%$ in girls, $p=0.002)$.

Table 3 presents the associations of mental health outcomes with female gender and rural residence in the combined rural-uran sample $(\mathrm{N}=1,705)$, adjusting for age, grade, height and weight. We also performed a sensitivity analysis that showed no statistically signifcance in any of the interaction terms (gender*residence) in the multivariate logistic regression models-therefore omitted from the table. Girls were less likely to have drunk alcohol in the past month (OR 0.65, $p=0.01)$, ever gotten drunk (OR $0.13, p$ $=0.02)$, ever gotten into trouble because of drinking (OR $0.40, p<0.001)$, smoked in the past month (OR $0.13, p<0.001)$, or experienced passive smoking in the past week (OR $0.74, p=0.03$. They were less likely to perceive their schoolmates as rarely or never helpful in the past month $(O R 0.47, p<0.001)$. They were less likely to have gotten into physical fights (OR $0.17, p<0.001$ ) or gotten injured $(O R=.65, p=0.01)$ in the past year, or suffered from bullying in the past month $(O R 0.68, p=0.01)$. Rural students were more likely to have ever gotten into trouble due to alcohol (OR5.09, $p=0.001)$. They were more likely to report 
frequent loneliness (OR 2.08, $p=0.03$ ), frequent insomnia (OR 2.07, $p=0.04$ ) and hopelessness for 2 weeks straight (OR 2.56, $p=0.04$ ) in the past year. They were more likely to perceive fellow schoolmates as rarely or never helpful (OR 2.90, $p=0.001)$, and their guardians as rarely or never understanding of their problems (OR 4.12, $p<0.001)$ in the past month. Finally, they were much more likely to have been seriously injured in the past year $(O R 5.00, p<0.001)$ and to have missed school unexcused in the past month (OR 5.21, $\mathrm{p}<0.001)$. 
Table 3

Prevalence of mental health outcomes in rural $(N=76)$ and urban $(N=1,629)$ students, ${ }^{*} p<0.05$ Number (\%) of students who...

Zhijin

(rural)

Beijing

value

Drug use

1. Recent drinking $\geq 1$

10

(urban)

0.41

$(13.3 \%)$

2. Ever drunk $\geq 1$

$7(9.2 \%)$

$158(10.3 \%)$

3. Trouble with alcohol $\geq 1$

11

$(14.9 \%)$

$119(7.3 \%)$

0.53

$3(3.9 \%)$

$60(3.7 \%)$

$<$

4. Recent smoking $\geq 1$

(63.2\%)

5. Passive smoking $\geq 1$

6. Other drugs $\geq 1$

$4(5.3 \%)$

$9(0.6 \%)$

$<$

$0.001^{*}$

Depression

7. Loneliness $\geq$ sometimes

25

$(32.9 \%)$

$427(26.3 \%) \quad 0.20$

8. Insomnia $\geq$ sometimes

19

$(25.3 \%)$

$322(19.8 \%) \quad 0.24$

9. Hopelessness $\geq 1$

24

$(32.0 \%)$

$294(18.2 \%) \quad 0.003^{*}$

10. Suicidal ideation $\geq 1$

$6(8.2 \%)$

$231(14.2 \%)$

0.15

11. Suicidal plan $\geq 1$

$3(3.9 \%)$

$114(7.0 \%)$

0.30

12. Close friends $=0$

$9(11.8 \%)$

$122(7.5 \%)$

0.17

13. Helpful schoolmates $=$ never/rarely

29

$(38.2 \%)$

14. Parental supervision $=$ never/rarely

35

$(46.1 \%)$

15. Parental understanding $=$ never/rarely

48

$(63.2 \%)$

Externalizing

behaviors
16. Fighting $\geq 1$

17. Injuries $\geq 1$

18. Bullying $\geq 1$

19. Absence $\geq 1$
16

$(21.1 \%)$

35

$(46.7 \%)$

36

$(47.4 \%)$

11

$(14.7 \%)$
$291(17.9 \%) \quad<.001 *$

$490(30.1 \%) \quad 0.003^{*}$

$553(34.0 \%)<$

$0.001^{*}$

$239(14.7 \%) \quad 0.13$

$218(16.2 \%)<$

$0.001^{*}$

$314(20.3 \%)<$

$0.001^{*}$

$78(4.8 \%) \quad<$ 
Table 4

Associations between mental health outcomes, gender and rural residence in combined analysis $(\mathrm{N}=$ $1,705)$.

\begin{tabular}{|c|c|c|c|c|c|}
\hline & & \multicolumn{2}{|l|}{ Girls vs. Boys } & \multicolumn{2}{|c|}{$\begin{array}{l}\text { Zhijin vs. Beijing } \\
\text { (rural) (urban) }\end{array}$} \\
\hline & & OR $(95 \% \mathrm{Cl})$ & $\begin{array}{l}\mathrm{p}- \\
\text { value }\end{array}$ & OR $(95 \% \mathrm{Cl})$ & $\begin{array}{l}\mathrm{p}- \\
\text { value }\end{array}$ \\
\hline \multirow[t]{6}{*}{ Drug use } & 1. Recent drinking $\geq 1$ & $\begin{array}{l}0.65(0.47- \\
0.89)\end{array}$ & $0.01 *$ & $\begin{array}{l}2.16(0.94- \\
4.99)\end{array}$ & 0.07 \\
\hline & 2. Ever drunk $\geq 1$ & $\begin{array}{l}0.13(0.02- \\
0.76)\end{array}$ & $0.02^{*}$ & $\begin{array}{l}2.82(0.99- \\
7.96)\end{array}$ & 0.05 \\
\hline & 3. Trouble with alcohol $\geq 1$ & $\begin{array}{l}0.40(0.25- \\
0.65)\end{array}$ & $<.001 *$ & $\begin{array}{l}5.09(1.87- \\
13.87)\end{array}$ & $0.001 *$ \\
\hline & 4. Recent smoking $\geq 1$ & $\begin{array}{l}0.13(0.06- \\
0.28)\end{array}$ & $\stackrel{<}{0.001 *}$ & $\begin{array}{l}2.02(0.44- \\
9.20)\end{array}$ & 0.36 \\
\hline & 5. Passive smoking $\geq 1$ & $\begin{array}{l}0.74(0.57- \\
0.97)\end{array}$ & $0.03^{*}$ & $\begin{array}{l}1.04(0.63- \\
1.70)\end{array}$ & 0.89 \\
\hline & 6. Other drugs $\geq 1$ & $\begin{array}{l}0.69(0.21- \\
2.29)\end{array}$ & 0.54 & $\begin{array}{l}9.20(0.74- \\
114.05)\end{array}$ & 0.08 \\
\hline \multirow[t]{7}{*}{ Depression } & 7. Loneliness $\geq$ sometimes & $\begin{array}{l}1.30(1.00- \\
1.69)\end{array}$ & 0.05 & $\begin{array}{l}2.08(1.09- \\
3.94)\end{array}$ & $0.03^{*}$ \\
\hline & 8. Insomnia $\geq$ sometimes & $\begin{array}{l}1.16(0.89- \\
1.52)\end{array}$ & 0.27 & $\begin{array}{l}2.07(1.19- \\
3.61)\end{array}$ & $0.01 *$ \\
\hline & 9. Hopelessness $\geq 1$ & $\begin{array}{l}0.90(0.74- \\
1.10)\end{array}$ & 0.32 & $\begin{array}{l}2.56(1.05- \\
6.23)\end{array}$ & $0.04^{\star}$ \\
\hline & 10. Suicidal ideation $\geq 1$ & $\begin{array}{l}1.17(0.87- \\
1.57)\end{array}$ & 0.29 & $\begin{array}{l}0.67(0.27- \\
1.65)\end{array}$ & 0.38 \\
\hline & 11. Suicidal plan $\geq 1$ & $\begin{array}{l}1.09(0.77- \\
1.56)\end{array}$ & 0.62 & $\begin{array}{l}0.60(0.18- \\
2.02)\end{array}$ & 0.41 \\
\hline & 12. Close friends $=0$ & $\begin{array}{l}0.80(0.47- \\
1.35)\end{array}$ & 0.40 & $\begin{array}{l}0.60(0.19- \\
1.84)\end{array}$ & 0.37 \\
\hline & $\begin{array}{l}\text { 13. Helpful schoolmates = } \\
\text { never/rarely }\end{array}$ & $\begin{array}{l}0.47(0.36- \\
0.61)\end{array}$ & $<.001 *$ & $\begin{array}{l}2.90(1.58- \\
5.34)\end{array}$ & $0.001 *$ \\
\hline \multirow[t]{2}{*}{ Social Support } & $\begin{array}{l}\text { 14. } \text { Parental supervision }= \\
\text { never/rarely }\end{array}$ & $\begin{array}{l}0.83(0.67- \\
1.05)\end{array}$ & 0.12 & $\begin{array}{l}1.74(0.91- \\
3.34)\end{array}$ & 0.09 \\
\hline & $\begin{array}{l}\text { 15. Parental understanding }= \\
\text { never/rarely }\end{array}$ & $\begin{array}{l}0.84(0.68- \\
1.05)\end{array}$ & 0.12 & $\begin{array}{l}4.12(2.12- \\
8.02)\end{array}$ & $<.001 *$ \\
\hline $\begin{array}{l}\text { Externalizing } \\
\text { behaviors }\end{array}$ & 16. Fighting $\geq 1$ & $\begin{array}{l}0.17(0.11- \\
0.27)\end{array}$ & $<.001 *$ & $\begin{array}{l}1.97(0.57- \\
6.88)\end{array}$ & 0.29 \\
\hline
\end{tabular}




\begin{tabular}{|c|c|c|c|c|}
\hline \multirow[b]{2}{*}{ 17. Injuries $\geq 1$} & \multicolumn{2}{|c|}{ Girls vs. Boys } & \multicolumn{2}{|c|}{$\begin{array}{l}\text { Zhijin vs. Beijing } \\
\text { (rural) (urban) }\end{array}$} \\
\hline & $\begin{array}{l}0.65(0.48- \\
0.88)\end{array}$ & $0.01^{*}$ & $\begin{array}{l}5.00(1.70- \\
14.76)\end{array}$ & $<$ \\
\hline 18. Bullying $\geq 1$ & $\begin{array}{l}0.68(0.51- \\
0.92)\end{array}$ & $0.01^{*}$ & $\begin{array}{l}2.75(1.00- \\
7.60)\end{array}$ & 0.05 \\
\hline 19. Absence $\geq 1$ & $\begin{array}{l}0.65(0.38- \\
1.11)\end{array}$ & 0.12 & $\begin{array}{l}5.21(2.39- \\
11.38)\end{array}$ & $<0.001 *$ \\
\hline
\end{tabular}

\section{Discussion}

This study used a unique rural sample from the poorest province in China to study the prevalence of mental health outcomes in underserved early adolescents, and to examine the associations between mental health, gender and rural residence by comparing this sample to a public urban sample. Major findings include: (1) 9/19 investigated mental health outcomes were found to be more prevalent in the rural sample compared to the urban sample; (2) rural residence was associated with significantly higher odds for 7/19 outcomes after adjusting for age, grade, weight and height; (3) girls were overall less likely to report drug use, poor peer support and externalizing behaviors but this gender difference was mostly driven by the urban sample.

In terms of drug use, the prevalence of alcohol use in the past month was similar in the rural (13.3\%) and the urban samples (10.3\%). However, the prevalence of having ever gotten into trouble due to alcohol was significantly higher in rural Zhijin $(14.9 \%$ vs. $3.7 \%, p<0.001)$. In the combined analysis, rural residence was also significantly associated with this outcome (OR 5.09, $p=0.001)$. These findings highlighted excessive drinking reaching harm as more likely in rural adolescents. Consequences of youth excessive drinking on a single occasion have been documented to range from poisoning to motor vehicle crash deaths, drownings and falls, suicides and burns to later dependency and injuries globally (Jernigan, 2001). Our findings were consistent with previous literature in many Chinese adolescents start drinking alcohol before 6th grade (Li et al., 1996). Therefore, alcohol use should be a priority target for mental health interventions, ideally starting before 6th grade and especially in rural China.

In terms of depressive symptoms, an alarming $32 \%$ of Zhijin students have felt "sad and hopeless almost every day for 2 weeks straight in the past year" (vs. 18.2\% in Beijing, $p=0.003$ ). In the combined analysis, rural residence was also significantly associated with this outcome (OR 2.56, $p=0.04)$. Though suicidal thought and planning were not significantly different between samples, hopelessness may be an early red flag for later depression (Mac Giollabhui et al., 2018). The combined analysis also showed that rural residence was associated with frequent insomnia (OR 2.07, $p=0.01$ ). Previous studies have shown insomnia as a predictor of depression in Chinese teenagers (Luo et al., 2014). Future interventions against adolescent depression could use insomnia as a measurable target in early adolescents especially in rural China, before clinical depression was evident. 
Under "social support", $38.2 \%$ of Zhijin students (vs. $17.9 \%$ in Beijing, $p<0.001$ ) rarely or never found their schoolmates helpful. $46.1 \%$ of them has little or no supervision on their free time (vs. $30.1 \%$ in Beijing, $p=$ 0.003 ) and more than $63.2 \%$ felt not understood by their guardians (vs. $34.0 \%$ in Beijing, $p<0.001$ ). In the combined analysis, rural residence was associated both with poor peer support (OR 2.90, $p=0.001$ ) and poor parental understanding (OR 4.12, $p<0.001$ ). Poor parental involvement and inadequate parenting practices have been shown to be modifiable mediators between socioeconomic status and child mental health, with a few published family-level programs that improved children's cognitive and socioemotional skills by optimizing parenting skills and involvement (Verhulst et al., 2020). On the other hand, peer relationships have been found as an effective buffer between traumatic life events and depression in Chinese teens (Greenberger et al., 2000), making it an important target for school-level interventions.

Under "externalizing behaviors", the prevalence of being bullied in the past month was $47.4 \%$ in rural Zhijin (vs. 20.3\% in Beijing, $\mathrm{p}$ < 0.001). The high rural prevalence was concerning for being much higher than the $13.3 \%$ previous estimate in China (Eslea et al., 2003), the $35.5 \%$ in neighboring LMICs such as the Philippines (Rudatsikira, 2008), and almost four times the $12 \%$ average in developed Western Europe (WHO, 2016). Bullying victimization in early teenage years have been shown to be associated with anxiety and depression (Bond et al., 2001), and with teenage suicidal ideation in a Chinse study (Liu et al., 2017). Given our findings in early adolescents, interventions targeting bullying should start at or before 12 yearsold. The prevalence of serious injuries was also much higher in the rural sample (46.7\% in Zhijin vs. $16.2 \%$ in Beijing, $p<0.001)$, confirmed by an OR of $5.0(p<0.001)$ associated with rural residence in combined analysis. One explanation is the risk of farm-work-related injuries in rural youth, with known associations to sleep disturbances and school-related stress (Postel et al., 2009). Other researchers suggested maltreatment by guardians and involvement in violent episodes as major risk factors (Shi et al., 2014). Injuries, in turn, can lead to unexplained school absenteeism, confirmed by our finding of OR 5.21 for missing school $(p<0.001)$ associated with rural residence. High absenteeism is likely to also involve anxiety, transport, bullying and difficulties with schoolwork (Melvin et al., 2019).

In terms of gender differences, combined analysis showed that girls were overall less likely to have drunk recently, to ever get drunk, to have drinking-related troubles, to smoke and to experience passive smoking. However, separate gender analysis by sample showed that most gender differences were noted in the urban sample alone, likely due to the relatively small size of our rural sample. The combined analysis findings were consistent with the global male predominance in smoking (WHO, 2010) and drinking (Wilsnack et al., 2009), as well as parallel findings in Chinese adolescents (Yue et al., 2016). Being a girl was overall associated with better perceived social support from their peers but not from their guardians. This was interesting because Chinese families are known to favor male children in resource-allocation (Tian et al., 2018). Perceived peer support is thus especially important for girls as it is a protective factor associated with increased prosocial behavior, better motivation and academic performance in school (Wentzel et al., 2004). Finally, girls had lower odds of suffering from physical fights, serious injuries and bullying. These findings were consistent with the literature on male predominance of externalizing behaviors in children (Chaplin \& Aldao, 2013). Overall, gender differences found in the combined analysis 
raise questions regarding the necessity to adopt different strategies and outcome measures by gender when designing future interventions.

This study has several strengths. First, its unique, underserved rural population from Guizhou has rarely been studied despite its needs and limited resources. Second, the combined analysis highlights the ruralurban inequality in adolescent mental health in China. Third, the GSHS survey covers a variety of mental health topics and has a wide international data base. Our findings help to add to the knowledge in adolescent mental health especially in LMICs. This study has a few important limitations. First, a crosssectional study is unable to confirm causality or temporality. Second, the specific rural Guizhou sample and urban Beijing sample may not be generalizable to other contexts. They are examples of health inequity in China due to social determinants of health. Third, the rural and urban samples were collected in different studies, although this was done using the same GSHS tool in anonymous data collection.

There is no reason to believe that the survey procedure may induce any difference. The comparison of the prevalence between samples may be affected by age distribution difference between your rural and urban sample. However, we were able to adjust the difference when estimating the ORs. Finally, the lack of information on internalized mental health measures and broader social-economic factors limited our ability to draw conclusions on important mental health outcomes such as anxiety, self-esteem and selfefficacy and the associations between outcomes and specific social determinants of health. More standardized, comprehensive mental health data in children and adolescents in LMICs are needed to understand the evolution of mental health in adolescents and their determinants.

\section{Conclusion}

This study is an examination of the prevalence of common mental health outcomes and their associations with gender and rural residence among early Chinese adolescents, using an underserved rural sample and a known public urban sample surveyed with the 2003 GSHS. Higher prevalence of excessive drinking, hopelessness, poor social support, and externalizing behaviors was found in rural adolescents compared to their urban peers. Girls had lower risks of drug use, poor peer support and externalizing behaviors. These findings call for targeted interventions informed by contextual and gender specifications.

\section{Declarations}

*Ethics approval and consent to participate

This study has been determined to have "exempt" status from the Stanford University IRB due to its lack of identifiable data and minimal risk with secondary data analysis from a previously collected sample and a public sample (please see attachment under supplementary files).

*Consent for publication

It was not possible to reach any individuals for consent due to the de-identified nature of our data. 
*Availability of data and material

The Zhijin data and materials are available in de-identified form upon reasonable request. The Beijing data and materials are publically available at https://www.cdc.gov/gshs/countries/westpacific/china.htm

${ }^{*}$ Competing interests

All authors declare no competing interests.

*Funding

The authors did not receive any funding.

*Authors' contributions

Dr. She was the originator of the project idea, participated in data collection, analysis and drafting of the manuscript. Dr. Zhao was key to project design, data collection as well as community distribution of preliminary results. Dr. Li was instrumental in the data analysis, drafting of the manuscript and edition of the final submission. All three authors have approved this submission for publication.

This manuscript has not been published and is not in submission to any other journal.

*Acknowledgements

We acknowledge the two local school principals, teachers and family members in rural Zhijin (China) who supported the original data collection for the rural sample (2013-2014).

*Authors information

The rural data collection was born of a collaboration between first and second authors starting in 2010 . At the time XS was a Public Health student helping DZ in a community health education project targeting teenagers entering puberty with various physical and psychological health challenges. DZ was the district medical officer and was deeply passionate about improving preventive care among community youth. XS completed her M.D. training in 2011 and kept communicating with DZ about way to help implement Public interventions that promoted school-age adolescent health. In 2013 XS volunteered to help obtain a baseline for student health at two local schools due to a lack of rural baseline data for measuring the impact of health-promoting programs. In 2014 the data collection was completed for the original baseline study and results were communicated to the community through the schools. Qualitative interviews with 18 community members including principals, teachers and parents during home visits revealed that Mental Health and the impact of gender-based expectations starting at a young age was one of the top three concerns for the community regarding early adolescent years. Therefore, after the publication of the original study, we decided to embark on this secondary analysis to focus on mental health and gender differences. 
The author(s) declared no potential conflicts of interest with respect to the research, authorship, and/or publication of this article.

This study was approved by the IRB at Stanford University School of Medicine and at the Zhijin County Medical Office.

All participants and authors have provided either written consent or verbal assent for publication. Data and mateiral are available for review upon request. This study did not receive any official research funding.

Dr. She contributed to the conception and design of the study, contributed to acquisition, analysis, and interpretation of data, drafted the manuscript, critically revised the manuscript for important intellectual content and gave final approval for publication. Dr. Zhao substantially contributed to acquisition, analysis, and interpretation of data, critically revised the manuscript for important intellectual content and gave final approval for publication. Dr. Li substantially contributed to the conception and design of the study, contributed to analysis and interpretation of data, critically revised the manuscript for important intellectual content and gave final approval for publication.

We gratefully acknowledge the contribution and generosity of the teachers, principals and families who participated in the survey in rural Zhijin, China and the salary support for the authors from Stanford University and the Zhijin Medical Office.

\section{References}

1. All-China Women's Federation. (2013). National survey of rural left-behind children and migrant children in china. beijing. ()

2. Bond, L., Carlin, J. B., Thomas, L., Rubin, K., \& Patton, G. (2001). Does bullying cause emotional problems? A prospective study of young teenagers.BMJ (Clinical Research Ed.), 323(7311), 480-484. doi:10.1136/bmj.323.7311.480 [doi]

3. Chaplin, T. M., \& Aldao, A. (2013). Gender differences in emotion expression in children: A metaanalytic review.Psychological Bulletin, 139(4), 735-765. doi:10.1037/a0030737 [doi]

4. Chen, L. J., Yang, D. L., \& Ren, Q. (2015). Report on the state of children in china. (No. 1). Chicago, IL: Chapin Hall at the University of Chicago.

5. Dong, Y., Bennett, K., Jan, C., Dong, B., Zou, Z., Hu, P., . . Ma, J. (2019). Subnational variation of stunting, wasting and malnutrition in chinese primary-school children between 2010 and 2014: Urban-rural disparity. Public Health Nutrition, 22(11), 2043-2054. doi:10.1017/S1368980019000235 [doi]

6. Erskine, H. E., Moffitt, T. E., Copeland, W. E., Costello, E. J., Ferrari, A. J., Patton, G., . . Scott, J. G. (2015). A heavy burden on young minds: The global burden of mental and substance use disorders 
in children and youth.Psychological Medicine, 45(7), 1551-1563. doi:10.1017/S0033291714002888 [doi]

7. Eslea, M., Menesini, E., \& Morita, Y. e. a. (2003). Friendship and loneliness among bullies and victims: Data from seven countries.Aggress Behav, 30, 71-83.

8. Fellmeth, G., Rose-Clarke, K., Zhao, C., Busert, L. K., Zheng, Y., Massazza, A., . . Devakumar, D. (2018). Health impacts of parental migration on left-behind children and adolescents: A systematic review and meta-analysis.Lancet (London, England), 392(10164), 2567-2582. doi:S0140-6736(18)32558-3 [pii]

9. Fleischmann, A., \& De Leo, D. (2014). The world health organization's report on suicide: A fundamental step in worldwide suicide prevention. Crisis, 35(5), 289-291. doi:10.1027/02275910/a000293 [doi]

10. Gao, Y., Li, L. P., Kim, J. H., Congdon, N., Lau, J., \& Griffiths, S. (2010). The impact of parental migration on health status and health behaviours among left behind adolescent school children in china.BMC Public Health, 10, 56-2458-10-56. doi:10.1186/1471-2458-10-56 [doi]

11. GBD 2015 Neurological Disorders Collaborator Group. (2017). Global, regional, and national burden of neurological disorders during 1990-2015: A systematic analysis for the global burden of disease study 2015. The Lancet.Neurology, 16(11), 877-897. doi:S1474-4422(17)30299-5 [pii]

12. Greenberger, E., Chen, C., Tally, S. R., \& Qi, D. (2000). Family, peer, and individual correlates of depressive symptomatology among U.S. and chinese adolescents. Journal of Consulting and Clinical Psychology, 68(2), 209-219. doi:10.1037//0022-006x.68.2.209 [doi]

13. Jernigan, D. (2001). Global status report: Alcohol and young people.(). Geneva: World Health Organization.

14. Kieling, C., Baker-Henningham, H., Belfer, M., Conti, G., Ertem, I., Omigbodun, O., . . Rahman, A. (2011). Child and adolescent mental health worldwide: Evidence for action.Lancet (London, England), 378(9801), 1515-1525. doi:10.1016/S0140-6736(11)60827-1 [doi]

15. Li, S., Zhu, C., \& Feldman, M. W. (2004). Gender differences in child survival in contemporary rural china: A county study.Journal of Biosocial Science, 36(1), 83-109. doi:10.1017/s0021932004006121 [doi]

16. Liu, X., Chen, G., Hu, P., Guo, G., \& Xiao, S. (2017). Does perceived social support mediate or moderate the relationship between victimisation and suicidal ideation among chinese adolescents? Journal of Psychologists and Counsellors in Schools, 27(123), 123-124-136. doi:10.1017/jgc.2015.30

17. Liu, H., Shi, Y., Auden, E., \& Rozelle, S. (2018). Anxiety in rural chinese children and adolescents: Comparisons across provinces and among subgroups. International Journal of Environmental Research and Public Health, 15(10), 10.3390/ijerph15102087. doi:E2087 [pii]

18. Luo, C., Zhang, J., \& Pan, J. (2013). One-year course and effects of insomnia in rural chinese adolescents.Sleep, 36(3), 377-384. doi:10.5665/sleep.2454 [doi]

19. Mac Giollabhui, N., Hamilton, J. L., Nielsen, J., Connolly, S. L., Stange, J. P., Varga, S., . . Alloy, L. B. (2018). Negative cognitive style interacts with negative life events to predict first onset of a major 
depressive episode in adolescence via hopelessness. Journal of Abnormal Psychology, 127(1), 1-11. doi:10.1037/abn0000301 [doi]

20. Maselko, J. (2017). Social epidemiology and global mental health: Expanding the evidence from high-income to low- and middle-income countries. Current Epidemiology Reports, 4(2), 166-173. doi:10.1007/s40471-017-0107-y [doi]

21. Melvin, G. A., Heyne, D., Gray, K. M., Hastings, R. P., Totsika, V., Tonge, B. J., \& Freeman, M. M. (2019). The kids and teens at school (KiTeS) framework: An inclusive bioecological systems approach to understanding school absenteeism and school attendance problems. Frontiers in Education, 4, 61.

22. Meng, X., \& Yamauchi, C. (2017). Children of migrants: The cumulative impact of parental migration on children's education and health outcomes in china.Demography, 54(5), 1677-1714. doi:10.1007/s13524-017-0613-z [doi]

23. National Bureau of Statistics of China. (2014). China regional economic development 2013 report (per capita GDP) . Retrieved from http://data.stats.gov.cn/english/swf.htm?m=turnto\&id=3

24. Patel, V., Kieling, C., Maulik, P. K., \& Divan, G. (2013). Improving access to care for children with mental disorders: A global perspective.Archives of Disease in Childhood, 98(5), 323-327. doi:10.1136/archdischild-2012-302079 [doi]

25. Postel, M. W., Jaung, M. S., Chen, G., Yu, S., Stallones, L., \& Xiang, H. (2009). Farm work-related injury among middle school students in rural china.Journal of Agricultural Safety and Health, 15(2), 129142. doi:10.13031/2013.26800 [doi]

26. Ren, X. S. (1995). Sex differences in infant and child mortality in three provinces in china.Social Science \& Medicine (1982), 40(9), 1259-1269. doi:027795369400232I [pii]

27. Rudatsikira, E., Mataya, R. H., Siziya, S., \& Muula, A. S. (2008). Association between bullying victimization and physical fighting among filipino adolescents: Results from the global school-based health survey.Indian Journal of Pediatrics, 75(12), 1243-1247. doi:10.1007/s12098-008-0244-x [doi]

28. Saxena, S., Paraje, G., Sharan, P., Karam, G., \& Sadana, R. (2006). The 10/90 divide in mental health research: Trends over a 10-year period. The British Journal of Psychiatry: The Journal of Mental Science, 188, 81-82. doi:S0007125000169211 [pii]

29. She, X., Zhao, D., \& Scholnick, J. (2016). Measuring the gap: A health assessment of rural chinese children compared to urban children. Global Pediatric Health, 3, 2333794X15625298. doi:10.1177/2333794X15625298 [doi]

30. Shi, Y., Zhang, L., Ma, Y., Yi, H., Liu, C., Johnson, N., . . Loyalka, P. \&. R.,S. (2015). Dropping out of rural china's secondary schools: A mixed-methods analysis. The China Quarterly, 224, 1048-1069.

31. Shi, X. Q., Qi, Y. H., Shi, D., Yan, C., Shi, J., Cao, B. L., .. Wang, H. Y. (2014). Features and risk factors of nonfatal injury among the rural children: A survey of seven schools in a mountain area in southwest china.PloS One, 9(7), e102099. doi:10.1371/journal.pone.0102099 [doi]

32. Tian, X., \& Yu, X. \& Klasen, S. (2018). Gender discrimination in china revisited: A perspective from family welfare 
.Journal of Chinese Economic and Business Studies, 16(1), 95-115.

doi:10.1080/14765284.2017.1410378

33. United Nations Population Fund. (2014). UNPFA annual report 2014. Retrieved from https://www.unfpa.org/annual-report-2014

34. US Center for Disease Control. (2016). China-global school-based student health survey. Retrieved from https://www.cdc.gov/gshs/countries/westpacific/china.htm

35. Verhulst, F. C., \& Tiemeier, H. (2020). Socioeconomic inequalities and mental health problems in children and adolescents. . In E. Taylor, F. Verhulst, J. Wong, K. Yoshida \& A. Nikapota (Eds.), Mental health and illness of children and adolescents. (pp. 1-2-18). Singapore: Springer.

36. Wentzel, K. R., Barry, C. M., \& Caldwell, K. A. (2004). Friendships in middle school: Influences on motivation and school adjustment.Journal of Educational Psychology, 96(2), 195-203. doi:10.1037/0022-0663.96.2.195

37. Wilsnack, R. W., Wilsnack, S. C., Kristjanson, A. F., Vogeltanz-Holm, N. D., \& Gmel, G. (2009). Gender and alcohol consumption: Patterns from the multinational GENACIS project.Addiction (Abingdon, England), 104(9), 1487-1500. doi:10.1111/j.1360-0443.2009.02696.x [doi]

38. World Health Organization. (2003). Global school-based student health survey (chinese version). Retrieved from https://www.cdc.gov/gshs/countries/westpacific/china.htm

39. World Health Organization. (2010). 10 facts on gender and tobacco.(). Geneva, Switzerland: WHO Department of Gender, Women and Health. Retrieved from https://www.who.int/gender-equityrights/en/

40. World Health Organization Regional Office for Europe. (2016). Fact sheet: Bullying and physical fights among adolescents. Retrieved from http://www.euro.who.int/_data/assets/pdf_file/0005/303485/HBSCNo.7_factsheet_Bullying.pdf?ua=1

41. Yue, Y., Hong, L., Guo, L., Gao, X., Deng, J., Huang, J., . . L Lu, C. (2015). Gender differences in the association between cigarette smoking, alcohol consumption and depressive symptoms: A crosssectional study among chinese adolescents.Scientific Reports, 5, 17959. doi:10.1038/srep17959 [doi]

42. Zhang, J., Qi, Q., \& Delprino, R. P. (2017). Psychological health among chinese college students: A rural/urban comparison. Journal of Child and Adolescent Mental Health, 29(2), 179-186. doi:10.2989/17280583.2017.1345745 [doi]

43. Zhao, C., Wang, F., Zhou, X., Jiang, M., \& Hesketh, T. (2018). Impact of parental migration on psychosocial well-being of children left behind: A qualitative study in rural china.International Journal for Equity in Health, 17(1), 80-018-0795-z. doi:10.1186/s12939-018-0795-z [doi]

44. Zhou, Y., \& Song, L. (2016). Income inequality in china: Causes and policy responses. China Economic Journal, 9(2), 186-187-208. doi:https://doi.org/10.1080/17538963.2016.1168203

45. Zhou, H., Mo, D., Zhou, C., Medina, A., Shi, Y., Zhang, L., \& Rozelle, S. (2016). The gender gap among school children in poor rural areas of western china: Evidence from a multi-province 
dataset.International Journal for Equity in Health, 15(1), 162-016-0442-5. doi:10.1186/s12939-0160442-5 [doi]

\section{Figures}

\begin{tabular}{|c|c|c|c|c|}
\hline & Prevalence (\%) of students who... & $\begin{array}{l}\text { Rural } \\
(\%)\end{array}$ & $\begin{array}{l}\text { Urban } \\
(\%)\end{array}$ & $\begin{array}{l}\text { Rural vs. } \\
\text { Urban } \\
\text { (Odds Ratio) }\end{array}$ \\
\hline \multirow{4}{*}{ Drugs } & $\begin{array}{l}\text { Had at least } 1 \text { alcoholic drink on } 1 \\
\text { or more days in the past } 30 \text { days }\end{array}$ & 13.33 & 10.34 & 1.06 \\
\hline & $\begin{array}{l}\text { Ever gotten really drunk in their } \\
\text { life }\end{array}$ & 6.56 & 5.48 & 1.22 \\
\hline & $\begin{array}{l}\text { Had hang-over, felt sick, got into } \\
\text { trouble as a result of alcohol }\end{array}$ & $14.86 * *$ & $3.70 * *$ & $7.28 * *$ \\
\hline & Used drugs one or more times & $5.26^{* *}$ & $0.56 * *$ & $8.54 * *$ \\
\hline \multirow{3}{*}{ Depression } & $\begin{array}{l}\text { Felt lonely most of the time or } \\
\text { always in } 12 \text { months }\end{array}$ & 11.84 & 6.83 & $2.10(p=0.06)$ \\
\hline & $\begin{array}{l}\text { Ever seriously considered } \\
\text { attempting suicide in } 12 \text { months }\end{array}$ & 8.22 & 14.22 & 0.68 \\
\hline & Have no close friends & $47.37 * *$ & $7.51 * *$ & $8.23 * *$ \\
\hline $\begin{array}{l}\text { Protective } \\
\text { Factors }\end{array}$ & $\begin{array}{l}\text { Parents or guardians never or } \\
\text { rarely knew what they were doing } \\
\text { with their free time in the past } 30 \\
\text { days }\end{array}$ & $68.06 * *$ & $51.48 * *$ & $1.81^{*}$ \\
\hline \multirow{3}{*}{$\begin{array}{l}\text { Externalizing } \\
\text { Behaviors }\end{array}$} & $\begin{array}{l}\text { Were in a physical fight } \geq 1 \mathrm{x} \text { in } \\
\text { the past } 12 \text { months }\end{array}$ & 21.05 & 14.67 & $1.58 *$ \\
\hline & $\begin{array}{l}\text { Were seriously injured } \geq 1 \mathrm{x} \text { in the } \\
\text { past } 12 \text { months }\end{array}$ & $46.67 * *$ & $16.20 * *$ & $4.64 * *$ \\
\hline & Were bullied $\geq 1 \mathrm{x}$ in 12 months & $47.37 * *$ & $20.35 * *$ & $4.01 * *$ \\
\hline
\end{tabular}

$$
*_{p<}=0.05 ; * *_{p}<=0.01
$$

Figure 1

Comparison of the prevalence of all mental health outcome measures by gender first in the rural sample, and then in the urban sample 


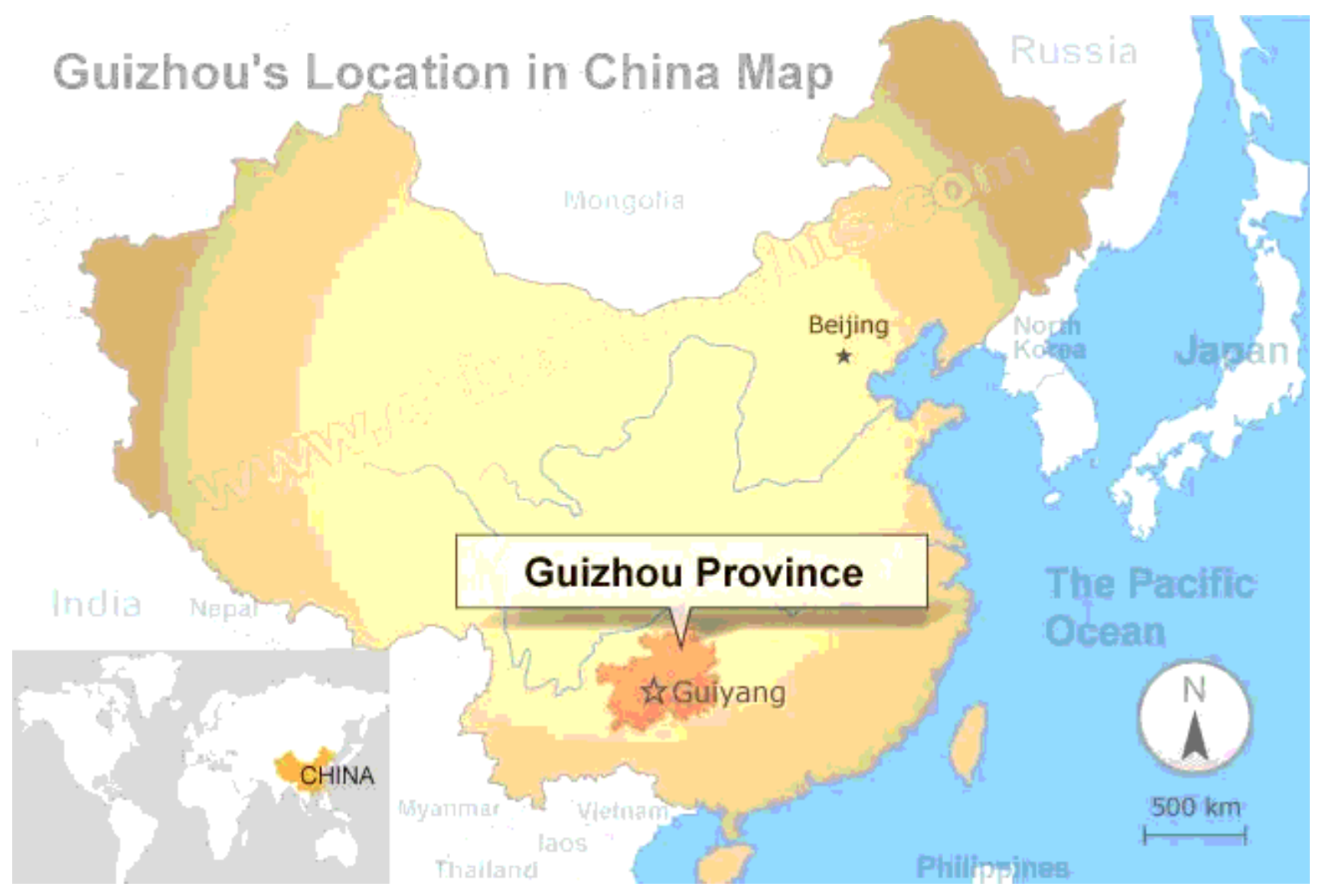

\section{Figure 2}

(Appendix 1) Map of Guizhou and Beijing. Note: The designations employed and the presentation of the material on this map do not imply the expression of any opinion whatsoever on the part of Research Square concerning the legal status of any country, territory, city or area or of its authorities, or concerning the delimitation of its frontiers or boundaries. This map has been provided by the authors.

\section{Supplementary Files}

This is a list of supplementary files associated with this preprint. Click to download.

- SupplementaryTable1.docx 